\title{
Mark Twain meets DSM-III-R: Conduct disorder, development, and the concept of harmful dysfunction
}

\author{
JOHN E. RICHTERS ${ }^{\mathrm{a}}$ AND DANTE CICCHETTI ${ }^{\mathrm{b}}$ \\ ${ }^{a}$ Child and Adolescent Disorders Research Branch, National Institute of Mental \\ Health; and $b_{M}$. Hope Family Center, University of Rochester
}

\begin{abstract}
The Diagnostic and Statistical Manual (3rd ed., rev.) (DSM-III-R) diagnosis of conduct disorder assumes that all children who engage in three or more criterion antisocial behaviors for 6 months or more suffer from a mental disorder. It resists all contextual information about a child's developmental history, capacities, strengths and circumstances, and assumes that the antisocial behavior necessarily stems from an underlying disorder. In this review, we use Mark Twain's narrative of the lives of Tom Sawyer and Huckleberry Finn as a point of departure for questioning the reasonableness of this assumption, and for examining normal as well as pathological pathways to antisocial behavior. We begin by reviewing the status of earlier controversies about the mental disorder concept in the service of documenting the impressive progress of the field in conceptualizing disorder. Next, we examine Wakefield's (1992a, 1992b) recently introduced "harmful dysfunction" concept of mental disorder and employ its criteria to evaluate the hypothesis that chronic antisocial behavior in childhood as defined by DSM-III-R is caused by an underlying mental disorder. We also examine some of the difficulties in discriminating between disorder- and nondisorder-based antisocial behavior, and consider issues that warrant attention in future theoretical and empirical work. Finally, we explore the pragmatic rather than scientific basis for DSM-III-R's mental disorder claim and argue that regardless of its status as a mental disorder, this most troubling and harmful behavior syndrome of childhood deserves the intensive interest, concern, and resources of the scientific and public health communities.
\end{abstract}

It would have been news to Tom Sawyer and Huckleberry Finn that they suffered from a mental disorder. Yet, from the opening scene of Mark Twain's The Adventures of Tom Sawyer (Twain, 187611950) through the closing chapters of The Adventures of Huckleberry Finn (Twain, 1947), we read about a sustained pattern of antiso-

While this article was being written, John Richters' automobile was stolen by an unknown adolescent whose mental health status remains a matter of speculation. Dante Cicchetti's work on this paper was supported by grants from the Prevention Research Branch of NIMH (MH45027) and the Spunk Fund, Inc. We gratefully acknowledge the assistance of Ken Richters in providing the behavioral details necessary to diagnosing Tom and Huck. We also thank Gene Arnold, Jim Breiling, Bernard Friedlander, Steve Hinshaw, Kimberly Hoag- cial behavior in both boys that would warrant a diagnosis of conduct disorder (CD) by the standards of contemporary psychiatry. Almost as though Twain had anticipated the Diagnostic and Statistical Manual (3rd ed., rev.) (DSM-III-R American Psychiatric Association, 1987) criteria for CD,

wood, Peter Jensen, Penny Krener, Jack Maser, Margot Moser, Sheree Toth, and Don Vereen for their thoughtful comments on an earlier draft of this paper. Finally, we thank Jerry Wakefield for some stimulating conversations about the harmful dysfunction concept. The opinions expressed here are those of the authors and do not necessarily represent the position of the National Institute of Mental Health. Requests for reprints may be sent to John Richters, Child and Adolescent Disorders Research Branch, NIMH, 5600 Fishers Lane, Room 10-104, Rockville, Maryland 20857. 
he managed to depict Tom and Huck each manifesting sufficient levels of antisocial behavior, including lying, stealing, aggression, truancy, running away, and even cruelty to animals-to warrant the diagnosis.

But, Twain also managed unwittingly to sow seeds of doubt about the CD diagnosis by rendering a rich and sympathetic narrative of the lives of Tom and Huck. We learn that Tom is an orphan being raised by his single aunt Polly, who is often bemused by his antics and who admits of her less than admirable disciplinary practices, "I ain't doin' my duty by that boy." Huck's misbehavior seems at least as easy to understand in context; his mother is deceased, and he receives nothing in the way of supervision, nurturance, or positive role modeling from his abusive father, the town drunk, whom he almost never sees. These biographical details would seem to offer a compelling explanation for the behavior of Tom and Huck as normal boys living and behaving under very abnormal circumstances. Yet, however compelling these details may seem, they are ignored in the decision to assign a diagnosis of CD. All children who engage in at least 3 of 13 antisocial behaviors over a $\&$ month period, regardless of history and circumstance, are diagnosed as suffering from the disorder. Although its exact nature and etiology are unspecified, the underlying disorder is nonetheless assumed to somehow cause the antisocial behavior (American Psychiatric Association, 1987, pp. xxii-xxiii).

The tension between Twain's sympathetic narrative and psychiatry's claim that Tom and Huck suffered from a mental disorder highlights fundamental questions concerning how we should define the boundaries between normal and pathological functioning in childhood. Questions such as this have been debated periodically throughout the history of medicine and science, most recently during the 1960's debate over the existence of mental illness (e.g., Ausubel, 197 1; Laing, 1967; Sarbin, 1967; Szasz, 1960). As we point out below, the chief lesson from earlier debates is that there are no fixed, immutable answers to questions concerning the boundaries between disorder and nondisorder. They warrant revisiting periodically on the basis of new experience, ideas, and data, much like ". . clearing turbid solutions by pouring them continually from one glass to the other" (Zubin, 1978, p. 3).

The issue of the boundary between normal and abnormal functioning is especially relevant to a developmental psychopathology perspective (Cicchetti, 1984; Cicchetti \& Toth, 1991; Rutter, 1986), which emphasizes knowledge of normal ontogenesis as necessary to an understanding of deviations or distortions from normality (Cicchetti \& Richters, 1993 [this issue]). Similarly, information obtained from studying pathology enhances understanding of normal development (Cicchetti, 1990).

This is an especially important time to reexamine the psychopathology issue with a particular focus on CD for two related reasons. First, since its introduction as a formal DSM category in 1980, the diagnosis of $\mathrm{CD}$ has gained considerable currency in research concerning antisocial behavior in childhood. This ascendancy will no doubt continue as the mental disorders of childhood play an increasingly influential role in organizing and interpreting mainstream research into both normal and abnormal development, and in establishing the funding and services delivery priorities of government agencies, professional organizations, and treatment providers (Cicchetti, 1984; Institute of Medicine, 1989; Richters \& Cicchetti, 1993 [this issue]). Because the disorder concept and attendant uses of terms such as diagnosis, symptom, treatment, and illness course have consequences for the ways we think and frame our questions about antisocial behavior in childhood, assumptions underlying the $\mathrm{CD}$ diagnosis warrant careful scrutiny. Second, the past two decades have given rise to a remarkably rich body of data concerning the psychological functioning of conduct-disordered children, their families, their social environments, their peer relationships, and their life-course trajectories. As a consequence, we are in a position to ask more informed 
and penetrating questions about the distinction between normal and psychopathological functioning than at any time in the past.

Several recent papers have examined closely the definitional boundaries of CD and its subtypes, as well as its relationship to other childhood disorders (see Achenbath, 1993; Hinshaw, Lahey, and Hart, 1993; Quay, 1993 [all in this issue]). In the discussion that follows we address the prior question of whether or not and under what circumstances it makes sense to conceptualize antisocial behavior in childhood as being caused by an underlying mental disorder. We begin by considering the more general concept of mental disorder, and the status of Szasz's earlier controversial thesis that mental disorders do not exist. An assessment of that thesis in light of present-day thinking and data provides a useful index of how far the field has progressed during the intervening decades. Next, we examine Wakefield's (1992a, 1992b) recently introduced harmful dysfunction concept of mental disorder, and employ its criteria to evaluate the hypothesis that chronic antisocial behavior in childhood as defined by DSMIII-R is caused by an underlying mental disorder. Finally, we examine some of the difficulties in discriminating between disorderand nondisorder-based antisocial behavior, and consider issues that warrant attention in future theoretical and empirical work in this area.

\section{The Concept of Mental Disorder}

The publication of Szasz's The Myth of Mental IIIness in 1960 marked a watershed event in the history of psychiatry (Szasz, 1960, 1971). By arguing the extreme position that mental disorders do not exist, Szasz provoked the field of psychiatry into struggling publicly with a poorly defined and overinclusive concept of mental illness that had plagued its past and threatened its future. Szasz's thesis was an admixture of social, political, and philosophical claims concerning psychiatry's misuse of medicine for social control. At its scientific core, however, was the claim that all physical dis- orders stem from identifiable physical lesions, defined as deviations or abnormalities in anatomical physical structures at either the microscopic (e.g., bacteria, cancer cells) or macroscopic (e.g., gross tumors, broken limbs) level. Because lesions had not been identified in connection with the behavior/symptom patterns labeled as mental illnesses, according to Szasz, there was no physical evidence that these behaviors were caused by real disorders. Thus, for Szasz, the presence of a physical lesion was necessary and sufficient for defining medical disorders; it therefore constituted a standard for evaluating the legitimacy of the mental disorder concept.

Critics noted important errors in this cornerstone of Szasz's position-errors based largely on an overly rigid, outmoded concept of medical illness (Kendell, 1975). First, it is not true that all physical lesions are considered disorders. Albinism, for example, is caused by the absence of an enzyme required in the metabolism of tyrosine, yet the resulting condition is not considered an illness per se. Similarly, children with fused second and third toes have a congenital defect similar to the one that causes spina bifida, yet because the ill effect is trivial it is not considered a disorder by conventional standards (Kendell, 1975). Other conditions, such as the sickle-cell trait, are positively beneficial in certain environments (e.g., those in which it protects against malaria) and are strictly harmful in others (e.g., those that are physically stressful). Second, there are numerous wellestablished medical disorders for which lesions have not yet been identified, including syndromes such as trigeminal neuralgia, senile pruritus, and dystonia musculorum deformans (torsion dystonia). The identifiedlesion criterion would require ignoring these as medical conditions until their underlying pathologies are identified. Moreover, it would have denied the physical illness status to other commonly recognized disorders such as epilepsy, Parkinson's disease, and pellagra, until their underlying pathologies were discovered after the turn of the century (Kendell, 1975). It also would have denied 
the disorder status to acquired immune deficiency syndrome (AIDS) until relatively recently. Finally, there are numerous diseases such as hypertension and diabetes that are not traceable to single, identifiable lesions in the traditional sense (Oldham, Pickering, Fraser Roberts, \& Sowry, 1960). Instead, they appear to be an emergent property of complex interactions among processes that, individually, may reflect only marginal, normal range deviance. Furthermore, disorders such as hypertension defy earlier notions of a qualitative distinction between health and illness and are more consistent with a dimensional model of pathology.

Kendell's counterexamples compel a more complex view of lesion-disorder linkage and an even broader conceptualization of the lesion concept than Szasz had assumed. Thus, rather than providing a standard for evaluating the legitimacy of mental disorders, it turns out that the medical illness concept itself is elusive. No simple definition of physical disorder is capable of encompassing all conditions recognized as disorders while at the same time excluding those that are not. The medical illness concept itself is a social construction on the boundary between biological facts and social values (Wakefield, 1992a, 1992b). Consequently, discourse over the legitimacy of mental disorders necessarily requires the development of a viable working definition of the more general concept of disorder.

\section{Disorder as Harmful Dysfunction}

The search for an adequate concept of disorder has led to a variety of definitional proposals, the most notable of which have differentially emphasized suboptimal functioning (Klein, 1978), statistical deviance (Cohen, 1981), unexpectable distress/disability (American Psychiatric Association [APA], 1980), and/or biological disadvantage (Kendell, 1975). Each, however, possesses severe limitations in its ability to accommodate noncontroversial disorders while excluding conditions widely considered not to be disorders. On the basis of a review and critique of these limitations, Wakefield has proposed an overarching, hybrid, harmful dysfunction concept of disorder, with an associated set of criteria for distinguishing between disorder and nondisorder in the domains of both physical and mental functioning:

A condition is a disorder if and only if (a) the condition causes some harm or deprivation of benefit to the person as judged by the standards of the person's culture ..., and (b) the condition results from the inability of some internal mechanism to perform its natural function, wherein a natural function is an effect that is part of the evolutionary explanation of the existence and structure of the mechanism. (Wakefield, 1992a, p. 384)

By preserving the strengths and discarding the weaknesses of earlier proposals, the harmful dysfunction concept holds several advantages over its predecessors. First, by focusing on a broadly defined concept of internal mechanisms, it adopts an evolutionary biology approach which acknowledges the brain and its functions as legitimate manifestations of biological mechanisms developed through natural selection (Buss, 1984). Although it assumes axiomatically that mental processes (e.g., cognition, emotion, perception) are ultimately traceable to underlying biological processes, it imposes no requirement to assess those processes at an anatomical or physiological level. Therefore, the harmful dysfunction concept is not yoked to the criterion of an identifiable (or identified, as in Szasz's requirement) physical lesion or any other single referent. Instead, it implicitly adopts a theoretical construct approach wherein a disorder is defined by the nomological network of laws that describe it, and is indexed by multiple, fallible indicators (Cronbach \& Meehl, 1955). Those constructs may be postulated in psychological or biological terms and may be indexed through biological and/or behavioral indicators at differing levels of abstraction. Consequently, the model is capable of accommodating both medical and mental disorders with equal ease.

Second, the harmful dysfunction con- 
cept emphasizes natural, evolved mechanisms within the individual that have gone awry. It therefore forces attention onto a specification of or speculation about those processes, and on the need to rule out alternative explanations in the form of normal functioning causal processes operating within, and environmental factors outside, the individual. It also minimizes the likelihood that conditions which are merely undesirable by social or political standards will be classified as disorders, as in the case of notable psychodiagnostic errors of the past such as drapetomania (the mental condition attributed to runaway slaves; Cartwright, 1981/1851; Szasz, 1971) and childhood masturbation disorder (Foucault, 1978). Finally, the harmful dysfunction criterion places on a firm scientific basis the distinction between disorder and other forms of human misery, unhappiness, and troubles.

It warrants underscoring that the concept of harmful dysfunction only circumscribes the conceptual decisions that must be made in discriminating disorders from nondisorders. It does not specify how those decisions are to be made. These decisions necessarily require an admixture of complex scientific and value judgments. The identification of dysfunction, for example, requires scientific knowledge or theory about the natural mechanisms in question and their functional significance, as well as criteria for determining the dysfunctional status of those mechanisms or processes.

Similarly, the harm requirement leaves open important questions concerning how to assess harmful effects and how to discriminate between the inability of a mechanism to perform its natural function and a mere production deficit of an intact mechanism. As Wakefield has noted, these decisions tend to be straightforward in the case of well-understood conditions and become more controversial and subject to scientific dispute to the extent that the underlying mechanisms and processes are not yet well understood (Wakefield, 1992a). This should alert us to the fact that, in the domain of mental disorders, tasks such as de- fining the domain of natural mechanisms, understanding the difference between normal variability and dysfunction, linking dysfunctions causally with harmful conditions, and even defining those harmful conditions, are likely to be matters of considerable scientific dispute. These questions, however, are not weaknesses in the harmful dysfunction concept itself. Rather, they are burdens that must be shouldered within the substantive domains of developmental psychopathology, evolutionary biology, and related disciplines (Buss, 1984; Cicchetti, 1984, 1989; Rutter, 1986).

\section{Competing Models of Antisocial Behavior}

The harmful dysfunction concept provides a useful heuristic framework for beginning to resolve the tension between Twain's characterization of Tom and Huck and the view of DSM-III-R. It encourages us to consider a range of alternatives in conceptualizing the causes of antisocial behavior, including factors within and outside the individual. In the discussion that follows we use the harmful dysfunction framework to consider the plausibility of both disorder-based and nondisorder-based models of antisocial behavior. First we focus on Wakefield's concept of harmful dysfunction, and employ its criteria to examine the hypothesis that chronic antisocial behavior in childhood is attributable to an underlying mental disorder. Next, we consider the possibility that the antisocial behavior of some children may be caused mainly by adverse environmental factors, unrelated to underlying dysfunctions within the child. Following this we examine some ambiguities of the harmful dysfunction concept and suggest how developmental considerations might come into play in resolving these issues.

\section{Model I: Antisocial behavior attributable to harmful dysfunctions}

Evidence for harm and deprivation of benefit. Although the DSM-III-R diagnosis of $\mathrm{CD}$ is defined exclusively in terms of a 
child's antisocial behavior, it is nonetheless associated with a wide array of harmful/ negative conditions in the domains of social, behavioral, emotional, and cognitive functioning. Moreover, to a striking degree these problems tend to appear early in life and continue across the life-span (Robins, 1966).

Childhood. Beginning as early as the preschool years, children who later display serious conduct problems have been shown to manifest significantly higher levels of impulsivity, irritability, and inattention than their peers-characteristics associated with negative interactions with parents, peers, and teachers (e.g., Campbell, 1991; Campbell, Breaux, Ewing, \& Szumowski, 1986; Patterson, Capaldi, \& Bank, 1991). During middle childhood, children with conduct problems are more likely to be rejected by their peers (Ladd, Price, \& Hart, 1990), develop poor relationships with their teachers, engender less nurturance and support within the school setting (Campbell, 1991), and suffer from academic deficiencies (Meltzer, Levine, Karniski, Palfreg, \& Clarke, 1984). These factors, in turn, have been shown to be associated with an increased likelihood of deviant peer group affiliations (Dishion, Patterson, \& Skinner, 1989), which itself has been implicated as a risk factor for substance abuse (Dishion \& Loeber, 1985), dropping out of school (Cairns, Cairns, \& Neckerman, 1989), and criminal behavior (Loeber \& Dishion, 1983; Loeber \& Stouthamer-Loeber, 1987).

In the clinical domain, children diagnosed with CD have been found to suffer from a range of emotional adjustment problems. A significant proportion of children diagnosed with $\mathrm{CD}$, for example, also warrant the diagnosis of attention-deficit hyperactivity disorder (ADHD), with its well-established functioning deficits in the domains of impulse control, difficulty sustaining attention, engaging in dangerous activities through apparent lack of foresight, and the like (Hinshaw, 1987; Hinshaw, et al., 1993 [this issue]; Loney, 1987). Moreover, children diagnosed with both $\mathrm{CD}$ and ADHD tend to suffer significantly higher functioning deficits in nearly all of the aforementioned domains than children with only a CD diagnosis (Hinshaw et al., 1993 [this issue]).

The diagnosis of $\mathrm{CD}$ also has been shown in epidemiological samples to be associated with higher than average risk for anxiety and depressive disorders (Zoccolillo, 1992). Whether these diagnoses themselves meet the harmful dysfunction criterion is less important in the present context than the fact that they are both associated with significant levels of personal distress and a range of noncontroversial functioning impairments. Finally, upwards of $90 \%$ of clinicreferred children diagnosed with earlyonset CD also may meet criteria for oppositional defiant disorder, a syndrome (regardless of its diagnostic status) associated with deficits in affect and behavior regulation and strained relations with peers as well as adults (Faraone, Biederman, Keenan, \& Tsuang, 1991; Loeber, 1988; Walker et al., 1991).

Adulthood. Robins has shown that approximately $31 \%$ of those who warrant the $\mathrm{CD}$ diagnosis as children remain sufficiently antisocial through adulthood to qualify for the diagnosis of antisocial personality disorder (ASP) after age 18. Their functioning deficits, based on epidemiological data, include significant levels of employment troubles (94\%), violence (SSOro), multiple moving traffic offenses (72\%), and severe marital difficulties (67\%) (Robins, 1966). Moreover, a significant proportion of the remaining $69 \%$ who do not warrant the ASP diagnosis may nonetheless suffer from a wide range of social dysfunctions in adult life. One recent study of adults, who met the criteria for CD in childhood and were raised in group homes, reported that only a minority (13\%) went on to show satisfactory social functioning in adult life (Zoccolillo, Pickles, Quinton, \& Rutter, 1992).

Interpreting harmful conditions. Much of what we know about the negative conditions associated with CD and antisocial behavior needs to be qualified by two important caveats. First, most findings have been 
based on samples of convenience, often including clinic-referred children who had been brought to the attention of therapists precisely because they were suffering from significant functioning impairments. Thus, although it is clear that some conductdisordered children suffer from numerous social and emotional problems, it is not clear to what extent these conditions are typical of the population of children diagnosable with CD. Related to this, some evidence indicates that many problems associated with $C D$ vary in prevalence and intensity as a function of various proposed subtypes, such as early onset CD (cf. Hinshaw et al., 1993 [this issue]; Moffitt, 1990) and undersocialized aggressive CD (cf. Quay, 1993 [this issue]). Most studies of children diagnosed with $\mathrm{CD}$, however, have been variable - rather than individualbased in their research designs and data analytic strategies. Consequently, results are often reported in terms of correlations, variance explained, and degrees of separation between distributions (a point to which we return later). It is therefore often difficult to estimate from reported data what proportion of children diagnosed with $\mathrm{CD}$ suffer from the conditions described.

Nonetheless, the evidence for multiple harmful conditions associated with some forms of antisocial behavior and CD in some individuals is compelling; on average, children diagnosed with $\mathrm{CD}$ are much more likely to experience more harm and deprivation of benefit than children with any of the other common syndromes and disorders of childhood. It is not enough, however, to demonstrate that harmful conditions are merely correlated with antisocial behavior. As we discuss in more detail later, the attribution of disorder requires a postulate or demonstration that the negative conditions are direct or indirect consequences of dysfunctions of natural processes within the child. A direct consequence might begin with an underlying deficit in arousal modulation that plays a causal role in producing symptoms of depression and anxiety as well as antisocial behavior; an indirect causal pathway might begin with dysfunctional learning mechanisms that play a causal role in producing antisocial behavior, the consequences of which lead to depression and/or anxiety. In both examples, the harmful consequences would be traceable to an underlying internal dysfunction, justifying the disorder attribution.

Evidence for dysfunctions in natural mechanisms. The concept of dysfunction within Wakefield's model of disorder refers specifically to the natural functions of mechanisms within the individual that have been favored by natural selection because of their adaptive significance in fostering reproductive fitness and survival. Just as the opposable thumb evolved as a consequence of the survival advantages that accrued to individuals who were better able to grasp and manipulate objects, executive functions of the nervous system were selected because of their contributions to survival (Dawkins, 1976)-but there is an important difference. Human executive functions such as the capacity for emotional expression and recognition, cooperation, bonding, selfawareness, learning from experience, anticipating the future, recognizing and avoiding danger, generating alternative strategies for action and choosing among them, social communication, and others do not have the same concrete physical referents as thumbs, hearts, and kidneys. Executive processes are anchored ultimately in biological reality. Metaphorically, however, they can be conceptualized usefully as the software of the nervous system. Stretching the metaphor somewhat, some basic executive processes may function as characteristics of an operating system (e.g., learning capacities), with others more analogous to programs (e.g., social cognitions). And because these systems do not exist in the same literal sense as thumbs, their complexity and emergent nature requires a different level of abstraction and discourse. The importance of this lies in the fact that there are innumerable alternative ways of conceptualizing the adaptive mechanisms of the nervous system and their dysfunctions. Furthermore, it is often difficult to know with any certainty whether 
or not a particular conceptualization truly carves nature at its joints by identifying the mechanisms most causally relevant to a given observable condition. Thus, any consideration of the nervous system's natural functions and their failures is necessarily limited by this indeterminacy.

A variety of underlying mechanisms central to the regulation of emotion, cognition, and behavior have been proposed as playing causal roles in the emergence and maintenance of conduct-disordered behavior, typically through interactions with adverse environmental conditions (see, e.g., Greenberg, Speltz, \& DeKlyen, 1993; Moffitt, 1993; Pennington \& Bennetto, 1993; Quay, 1993 [all in this issue]). In the discussion that follows, we review some of the empirical evidence for functioning deficits in each of these domains that have been shown to be associated with antisocial behavior. This review is not intended to be exhaustive but rather a sampling of the mechanisms in each domain. Furthermore, some of the associated research into mechanisms has focused on aggressive, antisocial, and delinquent children, rather than those diagnosed with CD per se. But findings in these areas nonetheless yield promising leads for more focused research on possible underlying dysfunctions of children diagnosed with CD.

Neuropsychological deficits. Numerous studies have shown a broad spectrum of neuropsychological deficits associated with delinquent and aggressive behavior in childhood, including deficiencies in attention modulation (Newman, 1987; Newman \& Howland, 1989), self-control and impulsivity (White, Moffitt, Caspi, Needles, \& Stouthamer-Loeber, in press), verbal skills, memory, IQ, and visual-motor integration (Moffitt \& Silva, 1988). Although neuropsychological differences between antisocial and nonantisocial children are often relatively mild, a study reported by Moffitt and her colleagues suggests the possibility that such deficits may be more striking for children who match the $\mathrm{CD}$ profile. In a representative sample of New Zealand boys, the authors reported an overall mean IQ difference between delinquents and non- delinquents. Closer scrutiny, however, revealed only a 1-point IQ deficit for transient delinquents, compared to a 17-point deficit for those who had also been aggressive in childhood (Moffitt, 1990a). There also was suggestive evidence in the New Zealand sample for an interaction between neuropsychological deficits and negative environmental factors. The combination of neurological deficits and adverse family life was associated with a fourfold increase in aggression over that found for boys characterized by either factor alone (Moffitt, 1990b).

Collectively, these and related findings reflect consistent yet mild evidence for neuropsychological deficits in heterogeneous groups of antisocial children, with evidence for more striking deficits in chronically antisocial children and among those living in adverse environments. It is worth noting that many of these deficits are unlikely to play a straightforward, direct role in stimulating or sustaining patterns of antisocial behavior per se. They instead may play significant roles farther back in the relevant causal chains and therefore earlier in children's lives (Moffitt, 1993 (this issue)). At present, the processes through which neuropsychological impairments exert their influences are largely a matter of informed speculation. As Moffitt has indicated, many of these mechanisms also have been linked to other aspects of cognitive, social, and emotional functioning problems, such as academic achievement (Rourke, 1985), noncompliance with parents (Kaler \& Kopp, 1990), and insecure attachment (Waters, Vaughn, \& Egeland, 1980) - processes which themselves have been linked to antisocial behavior (Greenberg et al., 1993; Reid, 1993 [both in this issue]). These complex interrelationships render difficult the task ahead of identifying whether or not, how, and to what extent neuropsychological deficits contribute to the development of antisocial behavior. But the fact that they have been identified so reliably as correlates of antisocial behavior warrants the hypothesis that they reflect underlying dysfunctions of natural mechanisms.

Psychobiological deficits. Similarly, with- 
in the related domain of psychobiology, Quay (1993 [this issue]) has summarized the growing body of data concerning possible brain dysfunctions in children with undersocialized aggressive CD (UACD) - a subtype characterized by unusual levels of physical aggression, codified in DSM-III but later discarded. Specifically, evidence from biochemical, psychophysiological, and experimental-behavioral studies of UACD children points to possible efficiency deficits in the brain's noradrenergic and serotonergic systems implicated in the activation and inhibition (respectively) of aggression. In the biochemical domain, for example, Kruesi and his colleagues reported significantly lower levels of the serotonin metabolite 5hydroxyindolacetic acid (CSF 5-HIAA) in children and adolescents hospitalized for disruptive disorders (including CD) compared to matched controls (Kruesi, et al., 1990). Moreover, lower levels of CSF 5-HIAA were strongly predictive of subsequent aggression at 2-year follow-up (Kruesi et al., 1992). These results are generally consistent with reports of an association between lower CSF 5-HIAA and both impulsivity and aggression in adults (e.g., Brown, Goodwin, Ballenger, Goyer, \& Major, 1979; Cocarro et al., 1989) and between CSF 5-HIAA and aggression in freeranging rhesus monkeys living under naturalistic conditions (Higley et al., 1992). These findings also converge with evidence showing that drugs used to reduce or increase serotonin levels in nonhuman primates tend also to increase or decrease aggression (respectively) (e.g., Chamberlain, Ervin, Pihl, \& Young, 1987; Raleigh, Brammer, Ritvo, Geller, McGuire, \& Yuwiler, 1986). Finally, several studies reported that electrodermal responses to external stimuli, an index of sympathetic activity reflecting processes related to anxiety and inhibition, tend to be diminished in groups of aggressive children and adolescents (e.g., Raine \& Venables, 1984; Raine, Venables, \& Williams, 1990).

Although plausible models have been introduced to explain how these processes might play an important role in causing an- tisocial behavior, much less attention has been devoted to the possibility that some instead may reflect either the consequences of antisocial behavior or bidirectional paths of influence (Susman, 1993 [this issue]). Nonetheless, the existing data render viable the hypothesis that some forms of CD may be influenced in important ways by underlying brain dysfunctions.

In the behavioral realm, several experimental studies reported by Quay and his colleagues have shown that UACD children are more likely than controls to perseverate to their disadvantage with previously rewarded behaviors in the face of punishment (e.g., Daugherty \& Quay, 1991; Shapiro, Quay, Hogan, \& Schwartz, 1988). These data converge with similar findings based on adult samples of incarcerated psychopaths, and with theoretical models of the role played by passive avoidance learning deficits in acquiring antisocial behavior patterns (e.g., Newman \& Kosson, 1986). Descriptively, these deficits are most parsimoniously interpreted as failures of learning in the context of carefully controlled laboratory tasks. Establishing the case that they reflect true dysfunctions in natural learning mechanisms will require additional evidence that they are temporally stable within individuals and across relevant settings, and instead do not reflect motivational deficits. At present, however, they provide tentative convergent support for the hypothesis of underlying dysfunction, by highlighting a specific form of learning deficit in at least some hyperaggressive conduct-disordered children.

Social cognition. In the domain of social cognition, Dodge and his colleagues have amassed a wealth of data demonstrating that children with conduct problems are more likely than their peers to be characterized by a wide variety of cognitive, perceptual, and attributional biases related to their conduct problems (Dodge, Bates, \& Pettit, 1990). Notable among these are social cognition deficits (e.g., Dodge, Pettit, McClaskey, \& Brown, 1986), inaccurate interpretations of peers' intentions (e.g., Dodge, Murphy, \& Buchsbaum, 1984), bi- 
ases toward assuming hostile intent in others (e.g., Lochman, 1987), failures to attend to relevant social cues (e.g., Dodge, Coie, Pettit, \& Price, 1990), misjudging aggression as a means to positive outcomes (Dodge et al., 1986), and deficient problemsolving skills and verbal-assertive strategies (e.g., Asarnow \& Callan, 1985). These are not isolated findings but, rather, stem from an intensive and systematic program of research into the mechanisms and processes underlying antisocial and aggressive behavior. In the context of that research, plausible roles have been posited for each of these processes in triggering and maintaining antisocial behavior tendencies.

In considering the relevance of these biases to the harmful dysfunction concept, however, it is useful to maintain a distinction between deficits inproduction and deficits in capacity. Although both may be of equal causal relevance to the initiation of antisocial behavior, the latter are more easily interpretable as underlying dysfunctions in the sense implied by the harmful dysfunction concept. Production deficits, in contrast, may reflect functioning tendencies that are engendered and/or rewarded by characteristics of a child's experiences and environment, but which are capable of functioning normally when those conditions no longer prevail. Regardless of whether or not they stem from underlying dysfunctions or adverse environmental factors, cognitive and perceptual biases leading to aggression may be useful and necessary targets for prevention and treatment efforts. But unless a persuasive case can be made that they reflect underlying dysfunctions in natural processes, the disorder attribution is unwarranted.

Another important consideration in evaluating social cognition biases is the possibility that they may reflect the consequences rather than the causes of antisocial behavior. That is, they may reflect selfjustifications for a history of aggressive or antisocial behavior. This hypothesis seems more plausible for some forms of cognitive and perceptual bias than others, but nonetheless warrants careful consideration among the range of alternatives to the harmful dysfunction hypothesis. Although many questions remain concerning the causal status of social cognition biases associated with antisocial behavior and aggression, plausible roles have been postulated for them in interpreting the social world and in generating and acting on behavioral strategies for negotiating that world.

Attachment. In the related domain of social-emotional development, several theorists have posited central etiological roles for children's attachment relationships in the development of disruptive behavior (Greenberg et al., 1993 [this issue]; Kagan, 1984; Richters \& Waters, 1991). These roles have included the effects of the child's internal representational models of attachment relationships on the formation and maintenance of their affective orientations to others, and their responsivity to positive socialization pressures. When children have a history of inadequate caregiving and insecure attachment relationships, their representational models of attachment figures and of the self in relation to others are likely to reflect their inadequate caregiving histories (Bretherton, 1985). Thus, rather than approaching the world in an unencumbered manner, these individuals may perceive their environments so as to be consistent with negative experiences (Crittenden, 1990). These expectations are likely to affect adversely the ability to respond to potentially positive situations or to enter into adaptive relationships, resulting in the emergence of negative social interactions and behavior patterns (Cicchetti, 1991; Lynch \& Cicchetti, 1991).

Findings such as these reflect only a sampling of the numerous deficiencies in internal processes and mechanisms that have been identified as correlates of antisocial behavior and/or conduct-disordered behavior. Moreover, each has been implicated in theoretical models as playing a direct or indirect role in the emergence and/or maintenance of at least some forms of the conduct-disordered behavior of some children. As others have noted, the available data suggest that clinically significant conduct 
problems are probably multiply determined by interactions among processes that are, in the case of child-parent attachment and certain neuropsychological deficits, sometimes several steps removed from more proximal causes of antisocial behavior (Greenberg et al., 1993; Moffitt, 1993 [both in this issue]). But this does not detract from their plausibility as candidates for the dysfunction hypothesis.

These data provide a compelling though tentative counterargument to the skeptical view that the classification of chronically antisocial behavior as a disorder is, as Blackburn characterized ASP, little more than ". . . a moral judgment masquerading as a clinical diagnosis" (Blackburn, 1988, p. 511). It is certainly true that most forms of antisocial behavior are objectionable by conventional social and moral standards, and that parental concern over such behavior is often the basis for clinical referral. These reasons alone, however, do not warrant our assent to the hypothesis that chronic antisocial behavior in childhood reflects an underlying mental disorder. Rather, the disorder hypothesis is justified by the cumulative and accumulating evidence that these behavior patterns are often associated with, and may stem from, underlying dysfunctions of natural processes within the individual. In the end, some of these processes may turn out to be transient consequences of adverse environments, and others may be judged as artifacts of processes that are themselves causally relevant. At present, however, they warrant the status of plausible candidates for the harmful dysfunction criterion in at least some forms of, and in certain individuals with, CD.

\section{Model 2: Antisocial behavior attributable to deviant environments}

The qualifiers some forms and certain individuals are significant because they underscore important limitations in our knowledge about the extent to which dysfunctions can account for the antisocial behavior of children diagnosed with CD. Those limitations include our incomplete knowledge of the most relevant underlying mechanisms, the tentative, speculative nature of our knowledge about the causal status of identified variables, and our limited ability to operationalize and measure many of the constructs we believe to be most relevant. Those limitations are also reflected in the fact that many of the identified harmful conditions and candidate mechanisms described earlier appear to be relatively mild correlates of conduct problems, with stronger associations found among children living in adverse environments. This suggests that there is probably considerable heterogeneity in the variety of causal factors and models operating within the population of children diagnosable with $\mathrm{CD}$. For some children, these and related mechanisms may be powerful determinants of antisocial behavior; for other children they may play secondary or tertiary roles; and for yet other children they may play no role. Not only is chronically antisocial behavior likely to be the end product of complex multifactorial processes operating within and outside a given individual, but the relevant causal processes are likely also to differ across individuals (Cicchetti \& Richters, 1993 [this issue]).

Although the harmful dysfunction framework focuses attention on underlying natural mechanisms that might account for antisocial behavior, it also invites our consideration of the possibility that some children might develop antisocial behavior patterns in the absence of internal dysfunctions; their conduct problems instead may be caused entirely by extrinsic, environmental factors. An obvious example of this might be children raised in criminogenic neighborhoods and/or families and those who engage in antisocial, even criminal, actions because those are the behaviors modeled, expected, and/or rewarded by the major influences in their environments (McCord, this issue). This is a particularly salient model to consider in late 20th century America, where in many major cities the allure of drug-related crime is ever present, and where gangs virtually control the social commerce and life of many neighborhoods. 
As scientists and clinicians, we know that gang involvement places children at risk for an unimaginable array of negative outcomes. But from the perspective of many children living in those neighborhoods, the real risks lie in not joining a gang, a decision that often can result in powerful social and physical penalties.

Moreover, the short-term payoffs for participating in criminal and/or gang activity can be exceedingly attractive, especially to those who are disenfranchised, are surrounded by violence and death, and see no realistic chance of access to the opportunity/payoff matrix available to those in mainstream society. The seductiveness of this type of allure was illustrated recently in the biography of Henry Hill, a New York gangster accepted into the Federal Witness Protection Program. As a young child, Hill's family lived across the street from a local mob hangout, providing him with a vantage point afforded to few in the neighborhood:

I was the luckiest kid in the world ... I was fascinated by the place. I used to watch them from my window, and I dreamed of being like them. At the age of twelve my ambition was to be a gangster. To be a wiseguy. To me being a wiseguy was better than being president of the United States. It meant power among people who had no power. It meant perks in a working-class neighborhood that had no privileges. To be a wiseguy was to own the world. I dreamed about being a wiseguy the way other kids dreamed about being doctors or movie stars or firemen or ballplayers. (Pileggi, 1985, p. 13)

Hill's lifelong pattern of antisocial and criminal behavior was sufficiently pervasive to warrant the diagnoses of $\mathrm{CD}$ in childhood and ASP as an adult. The question raised by his circumstances and account, however, is whether it is necessary, useful, or justified to attribute his behavior to an underlying mental disorder.' There is con-

1. Although DSM-III-R recognizes Hill's pattern of antisocial behavior as group-type $\mathrm{CD}$ (for which it includes no diagnostic criteria), it nonetheless still attributes the behavior to an underlying mental disorder. siderable room here for reasonable speculation about possible functioning deficits within Hill (e.g., deficient learning mechanisms, underactive inhibition system) that may have accounted for why he was so attracted to the criminal element. There also is ample reason to be wary of Hill's own account of his motivations (Farrington, 1993 [this issue]). But it is also easy to imagine how a normally functioning child exposed to those temptations - especially in conjunction with poor parent monitoring, supervision, and discipline - might be drawn into an antisocial and/or criminal life-style with mental processes intact, i.e., in the absence of an underlying dysfunction in the sense defined by Wakefield (1992a). We cannot know, of course, and we need not know in Hill's case. But the questions raised by his account are provocative, and warrant careful consideration in the case of tens of thousands of children living in equally seductive environments, often in conjunction with poor parenting and other social risk factors, whose antisocial and criminal behavior patterns are attributed by the DSM to an underlying mental disorder.

The example of Henry Hill and others like him highlights an important question that invariably arises in discussions of chronically antisocial children: Isn't a prolonged pattern of inherently dangerous, self-destructive behavior ipso facto evidence that there is something fundamentally wrong with a child? The answer depends very much on what we mean by "wrong." If wrong means that we find the behavior misguided, regrettable, morally repugnant, and a source of our concern about the child's values and welfare, then the term "wrong" certainly applies. But harmful behavior by itself is too broad a criterion for the attribution of an underlying mental disorder (Wakefield, 1992a, 1992b). There are numerous legal occupations that also place individuals at much higher than average risk for high levels of personal distress, physical harm, and even early death. Police officers, firefighters, rescue workers, soldiers, and missionaries are just a few notable examples of those who deliberately 
place themselves in harm's way on a regular basis. Yet we do not consider their behavior to be evidence of an underlying mental disorder. The reason is that we understand how the prevailing culture both values and rewards what they do. But this is no less true of the Henry Hills of the world. Mainstream society resists the notion that they can be fundamentally normally functioning human beings seduced by circumstance into deviant, antisocial life-styles. As Nicholas Pileggi understood, however, the deviant (from mainstream) values and reward structures of subcultures can be every bit as coherent and powerful in their effects as those of the mainstream culture:

For Henry and his wiseguy friends the world was golden. They lived in an environment awash in crime, and those who did not partake were simply viewed as prey. To live otherwise was foolish. Anyone who stood waiting his turn on the American pay line was beneath contempt. Those who did- who followed the rules, were stuck in low paying jobs, worried about their bills, put tiny amounts away for rainy days, kept their place, and crossed off workdays on their calendars like prisoners waiting their release could only be considered fools. ... Henry and his pals had long ago dismissed the idea of security and the relative tranquility that went with obeying the law. They exulted in the pleasures that came from breaking it. Life was lived without a safety net. They wanted money, they wanted power, and they were willing to do anything necessary to achieve their ends. (Pileggi, 1985, p. 37)

We need not accept Hill's outlook and behavior to allow that these may be the characteristics of a normally functioning individual who has adopted and adapted to a different world view and set of values than those endorsed by the main culture. To assume axiomatically that antisocial behavior must reflect an underlying mental disorder is to confuse different universes of discourse and frames of reference. It blurs important distinctions between moral/social deviance and psychopathology, evaluative judgments of behavior and underlying causes, issues of public health and science. Moreover, a failure to maintain these dis- tinctions jeopardizes any opportunity for constructing a meaningful concept of mental disorder, and stands as an obstacle to devising a coherent model of development and psychopathology.

\section{Discriminating Between Normal and Dysfunctional Pathways}

It would be equally wrong, however, to assume that all antisocial children living in such high-risk environments arrive at their behavioral dispositions through normal processes. Indeed, as indicated earlier, much of what we know about the predictors and correlates of antisocial behavior suggests that there are probably numerous pathological pathways as well. In fact, many of the neuropsychological, psychobiological, and social-emotional functioning deficits implicated earlier tend to cluster in precisely the same environments that offer inducements for antisocial behavior. Hence, as a practical matter discriminating between disorder- and nondisorder-based antisocial behavior in those environments may be a particularly challenging task.

Consider, for example, the early childhood profile of John Gotti, who as an adult would reign as godfather (the TefZon Don) of the largest, most powerful organized crime family in the United States. Gotti, currently in prison, has been known throughout his adult life as an exceptionally violent man even by organized crime standards. During his recent criminal trial in New York, eyewitness accounts, court testimony, and FBI wiretaps revealed a consistent pattern of extreme temper outbursts and vicious, brutal, uncontrolled violent behavior, often at the slightest provocation and often directed at those closest to him. It is less well known that Gotti's penchant for violence emerged very early in his elementary school years, which were marked by frequent fighting, a volcanic temper, and, according to his elementary school records, frequent disciplinary problems.

Teachers who first encountered the young John Gotti regarded his apparently uncontrollable 
temper as a severe handicap, for they saw an unusually bright boy (years later, his I.Q. would be measured somewhere around 140) who nevertheless had no interest in any school subject. ... Even in his preteen years (he) ... regarded everyone with a penetrating, baleful stare.

The boy seemed to be in some kind of constant rage, liable to erupt at the slightest provocation. (Cummings \& Volkman, 1992, pp. 18-19)

Even these scant biographical details about Gotti's childhood reveal a pattern of behavior strikingly similar to the undersocialized aggressive form of CD (Quay, 1993 [this issue]). In contrast to Henry Hill, for whom at least a plausible case can be made for nondisorder-based antisocial behavior, John Gotti's early behavior pattern seems less consistent with a normal pathway explanation and much more consistent with a dysfunction model along the lines discussed by Lahey, Quay, and others (Lahey, McBurnett, Loeber, \& Hart, in press; Quay, 1993 [this issue]). Again, we cannot know whether or not the different behavior patterns of Hill and Gotti warrant the particular explanations suggested here. However, it does seem reasonable to view those patterns as prototypical of children for whom we may need to entertain very different etiological models ranging from normal to pathological.

Even beyond the specifics of John Gotti's case, the normal pathway model generally seems less plausible for cases of childhoodonset than for adolescent-onset $\mathrm{CD}$. The earliest manifestations of antisocial behavior in early-onset children are often evident as early as the preschool years, typically in the form of significant levels of anger, irritability, defiance, and oppositionality (Greenberg et al., 1993; Hinshaw et al., 1993 [both in this issue]). Obviously, these behaviors do not necessarily signal an underlying disorder, but neither are they explainable by reference to the reinforcing values of a deviant subculture. They may, however, be engendered or reinforced by inconsistent or deviant parenting; they may be the early manifestations of temperament problems; or they may result from an inter- action between these. But whatever the matrix of causes, these behaviors are clear evidence of adjustment problems (often diagnosable as oppositional defiant disorder), and may for some children signal the existence or unfolding of an underlying dysfunction. The plausibility of this hypothesis derives from evidence that children diagnosed with early-onset CD are more likely to have a worse long-term prognosis (Robins, 1966), commit more crimes (Moffitt, in press), be more aggressive (Lahey et al., in press), and persist with antisocial behavior patterns into adulthood (Moffitt, in press; Robins, 1966) than children with lateonset CD.

\section{Discriminating Between Causes and Dysfunctions}

Although we can be reasonably certain that the disorder and nondisorder models each account for some proportion of the population of chronically antisocial children, there is no basis in the current literature for estimating their respective prevalences. The task, then, is to develop criteria for determining in individual cases whether or not there is a reasonable basis for the attribution of underlying disorder. Within the harmful dysfunction framework, the task of discriminating disorder from nondisorder hinges on an ability to identify the relevant natural mechanisms and to discriminate between normal variation and dysfunction in those mechanisms. In our earlier discussion, we described domains of neuropsychological, psychobiological, emotional, and social-cognitive performance in which deviations in functioning have been found to covary with antisocial behavior. Although we described plausible causal roles that have been postulated for these deviations in producing antisocial behavior, the terms cause and dysfunction are not synonymous within the harmful dysfunction framework.

Let us suppose, for example, the case of a nondisordered child who has nonetheless been drawn into a pattern of chronic antisocial behavior, which results in experiences 
that alter basic functioning characteristics of the child's nervous system. We can imagine that repeated exposure to aggression and dangerous, anxiety-producing stimuli might dampen the child's baseline levels of arousal and autonomic responses to fear signals. Suppose further that these changes or deviations in functioning actually facilitate the subsequent production of antisocial behavior. Perhaps they reduce anticipatory anxiety or fear when the child considers engaging in antisocial acts, and therefore increase the likelihood that those acts will be executed. Moreover, the child may experience an enhancement of performance in carrying out those acts, unencumbered by handicapping levels of arousal. We can predict with reasonable accuracy that a succession of such acts, facilitated by these deviations in functioning, will place the child at much higher than average risk for a variety of negative consequences. But is it reasonable to conceptualize these functioning deviations as underlying dysfunctions? The answer depends on how we define dysfunction. In one sense, they are adaptive in that they facilitate the performance of behaviors that an antisocial child was already disposed to engage in. In another sense, though, the changes can be seen as dysfunctional because they promote dysfunctional behaviors, that is, behaviors that place the child at risk for negative outcomes.

Before concluding in favor of the dysfunction interpretation, it is useful to consider Rotenberg's concept of differential insensitivities (Rotenberg, 1978). These are changes in autonomic functioning that are often naturally acquired through a process of systematic desensitization following repeated exposure to initially anxietyproducing stimuli. Normally, these are viewed as adaptive changes in the nervous system that facilitate performance in the presence of those stimuli. Emergency medical workers, nurses, and physicians, for example, undergo this process in the earliest stages of their training when they are first exposed to human cadavers, open wounds, and various other forms of normally arousing medical stimuli. They become desensi- tized to those experiences and as a consequence can perform their roles effectively in the presence of stimuli that would engulf the average layperson with debilitating levels of autonomic arousal.

It might be argued that the adaptations in medical personnel do not lead to harmful conditions, whereas the adaptations of the antisocial child do. This is true. But we can imagine the same desensitization processes taking place in the police recruits during their first months and years on the job, resulting in physiological functioning changes that facilitate their performance on the job. And when we consider that their duties place them at higher than average risk for personal distress, physical danger, calousness and early death, we are faced again with the same phenomenon with which we started. The police officer and the antisocial child each have experienced changes in their autonomic arousal systems that facilitate their performance of risk-taking behaviors. It is therefore difficult to escape the conclusion that the only functional difference between them (for present purposes) is our evaluative judgment of their behaviors.

It should be clear from this exercise why identifiable internal causes of antisocial behavior by themselves are an inadequate basis for the attribution of an underlying disorder. All behaviors, harmful and beneficial, are reflected in underlying physiological processes. It is therefore only a matter of time before we will be able to identify the physiological underpinnings of all manner of behavior. Thus, to equate the internal causes of harmful behavior with underlying disorder is to attribute all harmful behaviors to underlying disorders. It is for this reason that the harmful dysfunction concept directs attention to dysfunctions of natural mechanisms: the failure of natural mechanisms to function in the capacities for which they evolved, resulting in harm to the individual.

The emergent nature of many of the constructs we postulate in trying to understand behavior renders the identification of dysfunctions a challenging task. Not only are many of our constructs themselves distil- 
lates of multiple underlying processes (e.g., intelligence, inhibition), but also their effects on behavior are usually determined through interactions with other multipleprocess constructs (e.g., attachment, selfesteem) in the context of complex combinations of environmental factors. In extreme cases, it may be possible to make a persuasive case that the functioning of a particular process (e.g., very low intelligence, extremely poor arousal modulation) is truly dysfunctional and that its failures can be linked causally with observable harmful consequences. In many other instances, however, dysfunctions are likely to be located in theoretical space at an intersection of multiple interacting processes within and outside the individual. Moreover, the dysfunction is likely to be a product of processes that, individually, may function suboptimally but within the normal range.

\section{An organizational perspective}

These issues highlight the complexity inherent in identifying natural functions, and in conceptualizing failures in those functions in the sense called for by the harmful dysfunction concept. They also underscore the need for an integrative framework within which individual functions and their failures can be conceptualized in the broader context of development and functioning. The organizational approach to development provides a valuable heuristic for undertaking these tasks (Cicchetti \& Schneider-Rosen, 1986; Sroufe \& Rutter, 1984).

Just as the concept of dysfunction sharpens thinking about issues surrounding the conceptualization of disorder, the organizational perspective enhances an understanding of the concept of harmful dysfunction. Within an organizational perspective, development is best understood as a series of structural reorganizations within and among the biological, affective, cognitive, social, and representational systems (see Cicchetti \& Richters, 1993 [this issue]). The difference between the relatively immature person and a relatively mature one is the difference between a state of globality and lack of articulation, and a state of greater differ- entiation, articulation, and complexity, effectively organized into hierarchical systems and subsystems (Cicchetti \& Schneider-Rosen, 1986).

Given this view of development, it is clear that normality may not be conceived merely as conformity to the mean, because we may no more expect that the mean defines normal or healthy development than we can expect that the mean among physiological parameters defines health in organic medicine. 2 Rather, normal development must be seen in terms of structural changes within and among the child's biological and behavioral systems that reflect the dynamic interactions of changing biological, intrafamilial, social, and environmental variables, that given the absence of extraordinary environmental conditions, allow the child to attain competence.

In contrast, psychopathology is conceptualized as a lack of effective organization within and among biological and behavioral domains that leads to personal distress and/ or cognitive, affective, or social incompetence. Lack of organization between systems may be manifest either as a failure to achieve competence within one system, or as the incomplete resolution of certain developmental tasks within a system (Cicchetti \& Richters, 1993 [this issue]). When psychopathology is conceptualized in this manner, it is crucial to identify the specific developmental arrests or the unsuccessfully resolved developmental tasks implicated, the environmental stressors involved, and the biological and intrafamilial circumstances that may have interfered with the resolution of the developmental issues. Furthermore, it is essential to characterize each pathological disorder in terms of specific forms of nonintegration, in such a way as to distinguish it from other forms of psychopathology, each of which leaves its own fingerprint of incompetence by leading to peculiar patterns of maladaptation.

Note that this conceptualization of psy-

2. For example, even though dental caries and respiratory ailments are quite common in many human populations, they are nonetheless considered pathological (Wakefield, 1992a). 
chopathology acknowledges human development and functioning in its complexity and subtleness. In contrast to the dichotomous world of disorder/nondisorder in psychiatry, it recognizes that normality often fades into abnormality, adaptive, and maladaptive may take on differing definitions depending on whether one's time referent is immediate circumstance or longer term development, and that processes within the individual can be characterized as having shades or degrees of psychopathology. In short, the term psychopathology has had very different meanings in the literatures of psychiatry and developmental psychology, and the conceptual algorithm necessary for connecting the two remains an important task for future research and theory.

The organizational perspective already has proven useful in charting patterns of adaptation and maladaptation in longitudinal studies of high-risk (e.g., Down syndrome; maltreated) and clinical (e.g., depressed; attention deficit disorder) populations. For example, demonstrations that maltreated children fail to resolve successfully the stage-salient developmental issues of childhood (Cicchetti, Ganiban, \& Barnett, 1991), and that the offspring of parents with unipolar and bipolar mood disorders likewise manifest difficulties negotiating these tasks (Cicchetti, Toth, \& Bush, 1988; Radke-Yarrow \& Zahn-Waxler, 1990), provide striking evidence for the notion that these children are at high risk for a range of functioning deficits. Determining which forms of deficit under which conditions reflect underlying dysfunctions in the sense defined by the harmful dysfunction framework, however, remains an important task for future research (Cicchetti \& Richters, 1993 [this issue]).

Considerably more progress has been made in understanding the processes and mechanisms associated with insecure childparent attachment relationships. For example, avoidant and disorganized/disoriented attachment relationships with maltreating caregivers may be viewed as normal adaptations to very abnormal circumstances and patterns of care. At the same time, there is evidence that these children's relations with other adults (e.g., teachers) and peers are often problematic, suggesting that the insecure attachment relationship may be impacting adversely on other domains of social-emotional functioning, relatedness, and adaptation (Lynch \& Cicchetti, 1991). Thus, although there is nothing inherently disordered about insecure attachment relationships, there may be conditions under which the relevant underlying processes would qualify as harmful dysfunctions in the sense defined by Wakefield (Wakefield, 1992a). This remains an important question that is best understood and addressed within an organizational approach to development (Cicchetti \& Richters, 1993 [this issue]).

\section{The DSM-III-R and the Assumption of Underlying Mental Disorder}

The DSM-III-R assumption that mental disorder always underlies the behavior defined by $\mathrm{CD}$ stands in stark contrast to the complex, inherently developmental questions raised by the harmful dysfunction concept. This contrast begs the rather obvious question of what evidence there is for the DSMIII-R assumption in the case of CD. The short answer, as a reasoned review of the literature reveals, is that there is no sound basis; it is merely an assertion. The longer answer requires a brief consideration of what the DSM system is, what it is not, what it aspires to be, and what obstacles stand in the way of that aspiration.

\section{The DSM as an administrative document}

First, it is useful to remind ourselves occasionally that the DSM is fundamentally an administrative classification system for the human problems and conditions treated by mental health professionals (Richters \& Cicchetti, 1993 [this issue]). It provides a common language for communicating about these conditions among those within the mental health community and between that community and federal, state, and local public health agencies (but see Jampala, Sierles, \& Taylor, 1988; Morey \& Ochoa, 1989; Taylor, 1989). It also is used as a means for estimating the mental health 
needs of the nation, which in turn influences important decisions about the distribution of federal block grant funds to the states for services delivery.

Although surrounded by considerable controversy, the introduction of DSM in 1952 was a revolutionary and successful attempt by the APA to bring order and standards to the mental health community's conceptualization, definition, treatment, management, and communication about the varied conditions which for more than 100 years had gradually come under its care (Wilson, 1993). The desperate need for such a document at that time is obvious in the speed with which the DSM system was embraced by and became indispensable to the mental health community following its introduction. Although published criticisms of the specifics of the DSM on philosophical, theoretical, scientific, and even administrative grounds would fill shelves of library space, few would argue against the need for a standard classification and language system in the mental health community.

Given the pragmatic nature of the DSM system, it is no surprise that the conditions included in its first edition tended to be those with which clinicians were familiar in their day-to-day professional experience. 3 There was no logical test, no explicit inclusion criteria born of a coherent concept of mental disorder (Wakefield, 1992b). As Spitzer and his colleagues would later admit of the rather pragmatic inclusion process for DSM-III:

If there is general agreement among clinicians, who would be expected to encounter the condition, that there are a significant number of patients who have it and that its identification is important in their clinical work it is included in the classification. (Spitzer, Sheehy, \& Endicott, 1977, p. 5)

As the DSM system quickly became the legitimizing criterion for whether or not a

3. The intriguing question of why these were defined as mental disorders and not merely conduct problems or antisocial behavior is an even longer discussion that is not considered here. condition would qualify for third-party reimbursement, the scope of the manual broadened considerably and each subsequent revision ushered in a seemingly endless list of new conditions. Consequently, the present edition (DSM-III-R) includes conditions that range from commonly accepted forms of mental disease (e.g., schizophrenia) to more controversial conditions which, although legitimate sources of distress, seem to defy any coherent concept of mental disorder (e.g., developmental arithmetic disorder, developmental expressive writing disorder).

\section{The DSM as a scientific document}

It would be inaccurate, however, to characterize the DSM as only an administrative classification system. Indeed, from the beginning, its authors have aspired to develop and maintain a classification system that would also serve the research community. But there are really two dimensions to that aspiration that need to be evaluated separately. The first is an aspiration to have the DSM and its language system play a central role in the research enterprise, maximizing the likelihood that resulting findings can be translated into refinements to the classification system. This goal has been partly realized in the sense that the DSM system now plays a major, dominant organizing and communication role in research concerning virtually all so-called mental disorders. Moreover, it has had a major impact on changes to the mental disorders section of the International Classification of Diseases, helped justify and became the basis for the largest scale epidemiological study of adult psychiatric disorders ever undertaken, and will soon serve the same purpose in the study of disorders among children and adolescents (National Institute of Mental Health, 1993; Robins \& Regier, 1991; Wilson, 1993).

On the other hand, it has become clear that research findings and scientific consensus alone do not automatically translate into changes in the DSM classification sys- 
tern. Proposed changes must also survive the gauntlet of acceptability to clinicians, ease of usage in the mental health community, and at the same time not threaten the potential for third-party reimbursements for clinical services (Carson, 1991). These conditions are understandable yet formidable obstacles to the DSM's aspirations to become a scientifically based taxonomy of mental disorders. Ultimately, it may be obligated to too many constituencies with mutually incompatible demands to achieve fidelity as a taxonomy of mental disorders.

\section{The Boundary Between Science and Public Health}

The reimbursibility issue is particularly problematic because federal and private funding sourses for mental health treatment and services often require that a condition qualify as a mental disorder within the DSM system to qualify for payment. This requirement, in turn, creates an unnatural and counterproductive tension between the mental health, consumer advocate, and scientific communities-a tension that is nowhere more palpable than in the case of CD. In our earlier discussion, we demonstrated that the antisocial behavioral syndrome defined by the DSM-III-R CD criteria places children at high risk for a disturbing array of harmful outcomes ranging from tremendous personal distress and social-emotional problems to physical danger, imprisonment, and even early death. Moreover, these harms tend to radiate outward and afflict all those who come into contact with antisocial children - individuals, institutions, and society itself. These outcomes alone should be sufficiently compelling to warrant the attention and resources of the broadly defined mental health community. Within the current system, however, they are not sufficient reasons; the availability of resources often hinges on the classification of a condition as a mental disorder.

In light of the foregoing, it may seem surprising that the status of CD as a mental disorder has not stirred much controversy within the scientific community. The reason is fairly straightforward. Although the mental disorder designation creates a tension on the boundary between the scientific and public health communities, it typically is not an issue of consequence within the scientific community. The pattern of antisocial behavior defined by $\mathrm{CD}$ is a compelling focus of study not because of its status as a mental disorder, but because of its substantial deviation from normative development, its range of harmful consequences, its stability, and its resistance to change in a significant number of children. Thus, from a scientific perspective the phenomenon is equally interesting and worthy of study regardless of whether its causes and maintaining factors are due largely to hereditary influences, biological insults, adverse environments, or combinations of these.

Although this issue is seldom discussed in the published literature, most scientists are probably not committed to the assumption that the behavioral syndrome defined by $\mathrm{CD}$ is necessarily the product of an underlying mental disorder, e.g., McCord (this issue). Instead, the currency value and widespread usage of the diagnosis in most research contexts derive from the dual advantages of (a) using a common language and set of criteria for defining an important behavioral syndrome and (b) ensuring that research concerning the epidemiology, etiology, stability, sequelae, prevention, and treatment of chronic antisocial behavior will be valued, influential, and perceived as relevant to the public health, mental health, and research funding communities.

\section{Implications of the Mental Disorder Assumption}

Even though the value and significance of research under the guise of conduct disorder is unaffected by whether or not children manifesting the syndrome suffer from an underlying mental disorder, the assumption that they do nonetheless deserves careful scrutiny for several related reasons. First, as a matter of scientific principle, the mental 
disorder attribution is a strong epistemological claim that warrants the same empirical tests and challenges as any other claim to knowledge. We may choose to remain scientifically agnostic with respect to the mental disorder assumption in our use of the diagnostic label, but that usage is widely perceived to be tantamount to an endorsement and perpetuation of the underlying assumption. Moreover, it is a consequential tacit endorsement that inadvertently may serve to reinforce stereotyped views of the causes of antisocial behavior that can restrict the range of intervention and prevention options considered by treatment providers and policy agencies. It was only two decades ago that a medical advisor to then President Richard Nixon made a formal recommendation to the President to implement a government-sponsored mass screening of all 6- to 8-year-olds in the nation to detect "violent and homicidal tendencies," followed by unspecified corrective actions to be implemented in camps (Hutschnecker, 1969; Washington Post, 1970). Although Dr. Hutschnecker's proposal was not implemented, it is a reminder of how easily desperate solutions can spring from false assumptions about the causes of antisocial behavior.

Second, as an ethical issue, the mental disorder attribution carries with it significant, long-term negative social consequences for those afflicted (or labeled). We need only recall the political fate of U.S. Senator Eagleton several decades ago when his bid for the Vice-Presidency of the United States was derailed by evidence that he had once sought treatment for an affective disorder (Garmezy, 1978). Unfortunately, the stigmatization associated with mental disorders continues to play a significant role in the everyday lives of millions of Americans who are affected by mental illnesses. This potential for stigmatization, in conjunction with increasingly open access to information about the private lives of citizens, should make us very wary about the significant social costs of labeling a child as mentally ill to justify the resources of the mental health community.

Third, as a social issue, the mental disor- der attribution tends to focus attention on problems within the individual and away from pathological conditions in the environment that may, for some children, be largely responsible for their antisocial behavior. The United States is currently in the midst of an epidemic of violent crime, placing millions of children and adolescents at risk for its consequences (Cicchetti \& Lynch, 1993; Richters, 1993; Richters \& Martinez, 1993). Most major cities have suffered significant increases in violent crime in recent years, and the U.S. homicide rate among males aged 15-24 years now ranks it as the most violent country in the industrialized world (Fingerhut \& Kleinman, 1990). This violence and crime is far from random; most of it is committed by young adults, adolescents, and children who would easily meet the DSM criteria for ASP and CD, respectively. To attribute their behavior to an underlying mental disorder is to draw attention away from the criminogenic and pathological conditions that characterize their environments.

Fourth, the assumption of underlying disorder tends to have a more subtle yet powerful effect on constraining the questions that are asked and not asked by scientists about antisocial behavior. Like all assumptions, it has the chilling effect of bringing premature closure to inquiry.

\section{Conclusion}

Our purpose has been to bring to the foreground a long-neglected issue concerning children who are diagnosed (or are diagnosable) with CD, namely, the DSM-III-R assumption that all children who engage in the criteria1 behaviors of $\mathrm{CD}$ necessarily suffer from an underlying mental disorder (American Psychiatric Association, 1987, pp. xxii-xxiii). A review of the relevant issues and data leads to the reasonable conclusion that the DSM-III-R's strong assumption neither stems from nor is it supported by research findings. There is a compelling basis in the extant literature to warrant the hypothesis that some children diagnosed with CD suffer from underlying dysfunctions 
and that those dysfunctions play an important role in engendering and maintaining their chronic antisocial behavior. For the reasons outlined in this review, however, it is unclear at present what proportion of these children would meet the criteria for a coherent concept of mental disorder.

There are plausible theoretical and empirical reasons to postulate normal pathways to chronic antisocial behavior as well. That is, there may be a substantial number of chronically antisocial children raised in seductive, counterculture environments who pursue antisocial trajectories in the absence of an underlying disorder. As Meehl pointed out over three decades ago, they may be ". .. psychiatrically normal person[s] who learned the wrong cultural values from [their] neighborhood[s] and environment[s]" (Meehl, 1973/1959, p. 93). Whether particular pathways to antisocial behavior are normal or disordered, and whether or not initially-normal pathways translate into underlying disorder, remain important and complex empirical questions that have gone largely unexplored in the study of CD and antisocial behavior. We believe that Wakefield's concept of harmful dysfunction holds considerable potential for clarifying the most important questions in this pursuit (Wakefield, 1992a, 1992b) and that the developmental psychopathology framework yields a valuable heuristic for resolving these questions (Cicchetti \& Richters, 1993 [this issue]).

Finally, we turn to the question with which we began this discussion. Is it reasonable to assume that Tom Sawyer and Huck-

\section{References}

Achenbach, T. M. (1993). Taxonomy and comorbidity of conduct problems: Evidence from empirically based approaches. Development and Psychopathology, 5, 5 1-64.

American Psychiatric Association. (1980). Diagnostic and statistical manual of mental disorders (3rd ed.). Washington, DC: Author.

American Psychiatric Association. (1987). Diagnostic and statistical manual of mental disorders (3rd ed., rev.). Washington, DC: Author.

Ausubel, D. P. (1971). Personality disorder is disease. American Psychologist, 16, 59-74.

Becker, M. L. (1947). Introduction: How this book leberry Finn suffered from an underlying mental disorder? We prefer to let the issues raised in this paper speak for themselves and turn instead to the residents of fictional St. Petersberg who knew Tom and Huck best. Their evaluations were always stated in strictly social-moral terms, reflecting an innocence of sorts born of not having available to them our contemporary notions of mental disorder. The mothers of St. Petersberg judged Huck as "... idle, and lawless, and vulgar and bad." But the Widow Douglas, who had taken him in, was somewhat more sympathetic and was never quite able to decide whether Huck was "good, bad, or indifferent ." In contrast, everyone seemed more forgiving of Tom. His aunt Polly, in a moment of weakness, concluded "... he warn't bad, so to say, only mischeevous he warn't any more responsible than a colt ... he was the best hearted boy there ever was ."

Although Tom and Huck are well known as fictional characters in American literature, it is less well known that they are both based on real-life individuals. Huck, whose real name was Tom Blankenship, is rumored to have grown up to become a justice of the peace in the West (Becker, 1947). Tom Sawyer, on the other hand, actually was a composite of three real-life people. We know nothing about the eventual outcomes of two of them. But the third survived well into old age with his oppositionality, defiance, sense of irony, and "mischeevousness" intact. His name was Samuel Langhorne Clemens, and he wrote under the name of Mark Twain.

came to be written. In M. Twain, The adventures of Huckleberry Finn. Cleveland, OH: World Press. Blackburn, R. (1988). On moral judgments and personality disorders: The myth of psychopathic personality revisited. British Journal of Psychiatry, 153, 505-512.

Bretherton, I. (1985). Attachment theory: Retrospect and prospect. In I. Bretherton \& E. Waters (Eds.), Growing points of attachment theory and research. Monographs of the Society for Research in Child Development 50(1-2, Serial No. 209), 3-35.

Brown, G. L., Goodwin, F. K., Ballenger, J. C., Goyer, P. F., \& Major, L. F. (1979). Aggression in 
humans correlates with cerebrospinal fluid amine metabolites. Psychiatry Research, I, 131-139.

Buss, D. M. (1984). Evolutionary biology and personality psychology: Toward a conception of human nature and individual differences. American Psychologist, 39, 1135-1 147.

Cairns, R. B., Cairns, B. D., \& Neckerman, H. J. (1989). Early school dropout: Configurations and determinants. Child Development, 60, 1437-1452.

Campbell, S. B. (1991). Longitudinal studies of active and aggressive preschoolers: Individual differences in early behavior and in outcome. In D. Cicchetti \& S. L. Toth (Eds.), Rochester Symposium on Developmental Psychopathology: Vol. 2. Internalizing and externalizing expressions of dysfunction (pp. 57-89). Hillsdale, NJ: Erlbaum.

Campbell, S. B., Breaux, A. M., Ewing, L. J., \& Szumowski, E. K. (1986). Correlates and prediction of hyperactivity and aggression: A longitudinal study of parent-referred problem preschoolers. Journal of Abnormal Child Psychology, 14, 217-234.

Carson, R. C. (1991). Dilemmas in the pathway of the DSM-IV. Journal of Abnormal Psychology, 100, 302-307.

Cartwright, S. A. (1981/1851). Report on the diseases and physical peculiarities of the human race. In A. L. Caplan, H. T. Egelhart, Jr., \& J. J. McCartney (Eds.), Concepts of health and disease: International perspectives (pp. 305-326). Reading, MA: Addison-Wesley.

Chamberlain, B., Ervin, F. R., Pihl, R. O., \& Young, S. N. (1987). The effects of raising or lowering tryptophan levels on aggression in vervet monkeys. Pharmacology, Biochemistry, and Behavior, 28, 503-5 10.

Cicchetti, D. (1984). The emergence of developmental psychopathology. Child Development, 55, l-7.

Cicchetti, D. (1989). Developmental psychopathology: Some thoughts on its evolution. Development and Psychopathology, I, 1-4.

Cicchetti, D. (1990). Perspectives on the interface between normal and atypical development. Development and Psychopathology, 2(4), 329-333.

Cicchetti, D. (1991). Fractures in the crystal: Developmental psychopathology and the emergence of self. Developmental Review, 1 I, 27 l-287.

Cicchetti, D., Ganiban, J., \& Barnett, D. (1991). Contributions from the Study of High Risk Populations to Understanding the Development of Emotion Regulation. In J. Garber \& K. Dodge (Eds.), The development of emotion regulation and dysregulation (pp. 15-48). New York: Cambridge University Press.

Cicchetti, D., \& Lynch, M. (1993). Toward an ecologi$\mathrm{cal} /$ transactional model of community violence and child maltreatment: Consequences for children's development. Psychiatry, 56, \%- 118.

Cicchetti, D., 8z Richters, J. E. (1993). Developmental considerations in the investigation of conduct disorder. Development and Psychopathology, 5, 33 1344.

Cicchetti, D., \& Schneider-Rosen, K. (1986). An organizational approach to childhood depression. In M. Rutter, C. E. Izard, \& P. B. Read (Eds.), Depression in young people: Developmental and clinicalperspectives (pp. 71-134). New York: Guilford Press.
Cicchetti, D., \& Toth, S. L. (1991). The making of a developmental psychopathologist. In J. Cantor, C. Spiker, \& L. Lipsitt (Eds.), Child behavior and development: training for diversity (pp. 34-72). Norwood, NJ: Ablex.

Cicchetti, D., Toth, S. L., \& Bush, M. (1988). Developmental psychopathology and incompetence in childhood: Suggestions for intervention. In B. Lahey \& A. Kazdin (Eds.) Advances in clinical child psychology (Vol. 11, pp. 1-71). New York: Plenum Press.

Cocarro, E. F., Siever, L. J., Klar, H. M., Maurer, G., Cochrane, K., Cooper, T. B., Mohs, R. C., \& Davis, K. L. (1989). Serotonergic studies in patients with affective and personality disorders: Correlates with suicidal and impulsive aggressive behavior. Archives of General Psychiatry, 46, $587-$ 599.

Cohen, H. (1981). The evolution of the concept of disease. In A. L. Caplan, H. T. Engelhardt, Jr., 8z J. J. McCartney (Eds.), Concepts of health and disease: Interdisciplinary perspectives (pp. 209220). Reading, MA: Addison-Wesley.

Crittenden, P. (1990). Internal representational models of attachment relationships. Infant Mental Health Journal, I I, 259-277.

Cronbach, L. J., \& Meehl, P. E. (1955). Construct validity in psychological tests. Psychological Bulletin, 52, 281-302.

Cummings, J., \& Volkman, E. (1992). Goombata: The improbable rise and fall of John Gotti and his gang. New York: Avon Books.

Daughterty, T. K., \& Quay, H. C. (1991). Response perseveration and delayed responding in childhood behavior disorders. Journal of Child Psychiatry and Psychology, 32, 453-461.

Dawkins, R. (1976). Theselfish gene. Oxford: Oxford University Press.

Dishion, T. J., \& Loeber, R. (1985). Adolescent marijuana and alcohol use: The role of parents and peers revisited. American Journal of Drug and Alcohol Abuse, II, 11-15.

Dishion, T. J., Patterson, G. R., \& Skinner, M. S. (1989, April). A process model for the role of peers in adolescent social adjustment. Paper presented at the biennial meeting of the Society for Research in Child Development, Kansas City, MO.

Dodge, K. A., Bates, J., \& Pettit, G. S. (1990). Mechanisms in the cycle of violence. Science, 250, 16781683.

Dodge, K. A., Coie, J. D., Pettit, G. S., \&Price, J. M. (1990). Peer status and aggression in boys' groups: Developmental and contextual analyses. Child Development, 6I, 1289-1309.

Dodge, K. A., Murphy, R. R.,\& Buchsbaum, K. (1984). The assessment of intention-cue detection skills in children: Implications for developmental psychopathology. ChildDevelopment, 55, 163-173.

Dodge, K. A., Pettit, G. S., McClaskey, C. L., \& Brown, M. (1986). Social competence in children. Monographs of the Society for Research in Child Development, 51 (2, Serial No. 213).

Faraone, S. V., Biederman, J., Keenan, K., \&Tsuang, M. T. (1991). Separation of DSM-III attention deficit disorder and conduct disorder: Evidence from a family genetic study of American child psychiatry patients. Psychological Medicine, 21, 109-121. 
Farrington, D. P. (1993). Motivations for conduct disorder and delinquency. Development and Psychopathology, 5, 225-241.

Fingerhut, L. A., \& Kleinman, J. C. (1990). International and interstate comparisons of homicide among young males. Journal of the American Medical Association, 263, 3292-3295.

Foucault, M. (1978). History ofsexuality: Vol. 1. An introduction. New York: Pantheon.

Garmezy, N. (1978). Never mind the psychologists: Is it good for the children? The Clinical Psychologist, $3 Z(3-4), \quad l-6$.

Greenberg, M. T., Speltz, M. L., \& DeKlyen, M. (1993). The role of attachment in the early development of disruptive behavior problems. Development and Psychopathology, 5, 191-213.

Higley, J. D., Mehlman, P. T., Taub, D. M., Higley, S. B., Suomi, S. J., Linnoila, M., \& Vickers, J. H. (1992). Cerebrospinal fluid monoamine and adrenal correlates of aggression in free-ranging rhesus monkeys. Archives of General Psychiatry, 49,436441 .

Hinshaw, S. (1987). On the distinction between attentional deficits/hyperactivity and conduct problems/aggression in child psychopathology. Psychological Bulletin, 101, 443-463.

Hinshaw, S. P., Lahey, B. B., \& Hart, E. L. (1993). Issues of taxonomy and comorbidity in the development of conduct disorder. Development and Psychopathology, 5, 3 l-49.

Hutschnecker, A. (1969). A plan for prevention of crime. Memo to the President of the United States on the Eisenhower Commission on Crime.

Institute of Medicine. (1989). Research on children and adolescents with mental, behavioral, and developmental disorders. Washington, DC: National Academy Press.

Jampala, V., Sierles, F., \& Taylor, M. (1988). The use of DSM-III-R in the United States: A case of not going by the book. Comprehensive Psychiatry, 29, 39-47.

Kagan, J. (1984). The nature of the child. New York: Basic Books.

Kendell, R. E. (1975). The concept of disease and its implications for psychiatry. British Journal of Psychiatry, 127, 305-3 15.

Klein, D. F. (1978). A proposed definition of mental illness. In R. L. Spitzer \& D. F. Klein (Eds.), Critical issues in psychiatric diagnosis (pp. 41-7 1). New York: Raven Press.

Kruesi, M. J. P., Hibbs, E. D., Zahn, T. P., Keysor, C. S., Hamburger, S. D., Bartko, J. J., \& Rapoport, J. L. (1992). A two-year prospective follow-up study of children and adolescents with disruptive behavior disorders: Prediction by cerebrospinal fluid 5-hydroxyindoleacetic acid, homovanillic acid, and autonomic measures. Archives of General Psychiatry, 49, 429-435.

Kruesi, M. J. P., Rapoport, J. L., Hamburger, S. D., Hibbs, E. D., Potter, W. Z., Lenare, M., \& Brown, G. L. (1990). Cerebrospinal fluid monoamine metabolites, aggression, and impulsivity in disruptive behavior disorders of children and adolescents. Archives of General Psychiatry, 47,419-426.

Ladd, G. S., Price, J. M., \& Hart, C. H. (1990). Preschooler's behavioral orientations and patterns of peer control: Predictive of peer status? In S. R.
Asher \& J. D. Coie (Eds.), Peer rejection in childhood (pp. 90-115). Cambridge: Cambridge University Press.

Lahey, B. B., McBurnett, K., Loeber, R., \& Hart, E. L. (in press). Psychobiology of conduct disorder. In G. P. Sholeuar (Ed.), Conduct disorders in children and adolescents: Assessments and interventions. American Psychiatric Press.

Laing, R. D. (1967). The politics of experience. London: Penguin Books.

Lochman, J. E. (1987). Self and peer perceptions and attributional biases of aggressive and non-aggressive boys in dyadic interactions. Journal of Consulting and Clinical Psychology, 55, 404-410.

Loeber, R. (1988). Natural histories of conduct problems, delinquency, and associated substance use: Evidence for developmental progressions. In B. B. Lahey \& A. E. Kazdin (Eds.), Advances in clinical childpsychology (Vol. 11, pp. 73-124). New York: Plenum Press.

Loeber, R., \& Dishion, T. J. (1983). Early predictors of male delinquency: A review. Psychological Bulletin, 74, 68-99.

Loeber, R., \& Stouthamer-Loeber, M. (1987). Prediction. In H. C. Quay (Ed.), Handbook of juvenile delinquency (pp. 325-382). New York: Wiley.

Loney, J. (1987). Hyperactivity and aggression in the diagnosis of attention deficit disorder. In B. B. Lahey \& A. Kazdin (Eds.), Advances in clinical child psychology (Vol. 10, pp. 99-135). New York: Plenum Press.

Lynch, M., \& Cicchetti, D. (1991). Patterns of relatedness in maltreated and nonmaltreated children: Connections among multiple representational models. Development and Psychopathology, 3 , 19-30.

McCord, J. (1993). Conduct disorder and antisocial behavior: Some thoughts about processes. Development and Psychopathology, 5, 321-329.

Meehl, P. E. (1973/1959). Some ruminations of the validation of clinical procedures. In P. E. Meehl (Ed.), Psychodiagnosis: Selected papers (pp. 90116). Minneapolis: University of Minnesota Press.

Meltzer, L. J., Levine, M. D., Karniski, W., Palfreg, J. S., \&Clarke, S. (1984). An analysis of the learning style of adolescent delinquents. Journal of Learning Disabilities, 17, 600-608.

Moffitt, T. E. (1990a). Juvenile delinquency and attention-deficit disorder: Developmental trajectories from age 3 to 15. Child Development, 62,893-910.

Moffitt, T. E. (1990b). The neuropsychology of delinquency: A critical review of theory and research. In N. Morris \& M. Tonry (Eds.), Crime and justice (Vol. 12, pp. 99-169). Chicago: University of Chicago Press.

Moffitt, T. E. (1992). "Life-course-persistent" and "adolescent-limited" antisocial behavior: A developmental taxonomy. Psychological Review.

Moffitt, T. E. (1993). The neuropsychology of conduct disorder. Development and Psychopathology, $5,135-151$.

Moffitt, T. E., \& Silva, P. A. (1988). IQ and delinquency: A direct test of the differential detection hypothesis. Journal of Abnormal Psychology, 97, 330-333.

Morey, L., \& Ochoa, E. (1989). An investigation of adherence to diagnostic criteria: Clinical diagnosis of 
the DSM-III-R personality diagnosis. Journal of Personality Disorders, 3, 180- 192.

National Institute of Mental Health. (1993). Request for applications: Cooperative agreement for epidemiological research into child and adolescent mental disorders. Washington, DC: Author.

Newman, J. P. (1987). Reaction to punishment in extroverts and psychopaths: Implications for the impulsive behavior of disinhibited individuals, Journal of Research in Personality, 21, 464-480.

Newman, J. P., \& Howland, E. (1989). The effect of incentives on Wisconsin card sorting task performance in psychopaths. Unpublished manuscript, University of Wisconsin at Madison.

Newman, J. P., \& Kosson, D. S. (1986). Passive avoidance learning in psychopathic and nonpsychopathic offenders. Journal of Abnormal Psychology, 95, 257-263.

Oldham, P. D., Pickering, G., Fraser Roberts, J. A., \& Sowry, G. S. C. (1960). The nature of essential hypertension. Lancet, ii, 877-882.

Patterson, G. R., Capaldi, D., \& Bank, L. (1991). An early starter model for predicting delinquency. In D. Pepler \& K. H. Rubin (Eds.), The development and treatment of childhood aggression (pp. 139168). Hillsdale, NJ: Erlbaum.

Pennington, B. F., \& Bennetto, L. (1993). Main effects or transactions in the neuropsychology of conduct disorder? Commentary on "the neuropsychology of conduct disorder." Development and Psychopathology, 5, 153-164.

Pileggi, N. (1985). Wiseguy: Life in a mafia family. New York: Pocket Books.

Quay, H. C. (1993). The psychobiology of undersocialized aggressive conduct disorder: A theoretical perspective. Development and Psychopathology, $5, \quad 165-180$.

Radke-Yarrow, M., \& Zahn-Waxler, C. (1990). Research on children of affectively ill parents: Some considerations for theory and research on normal development. Development and Psychopathology, 2, 349-366.

Raine, A., \& Venables, P. H. (1984). Electrodermal non-responding, antisocial behavior and schizoid tendencies in adolescents. Psychophysiology, 22, 424-433.

Raine, A., Venables, P. H., \& Williams, M. A. (1990). Autonomic orienting responses in 15-year-old male subjects and criminal behavior at age 24. American Journal of Psychiatry, 147, 933-937.

Raliegh, M. J., Brammer, G. L., Ritvo, E. R., Geller, E., McGuire, M. T., \& Yuwiler, A. (1986). Effects of chronic fenfluramine on blood serotonin, cerebrospinal fluid metabolites, and behavior in monkeys. Psychopharmacology, 90, 503-508.

Reid, J. B. (1993). Prevention of conduct disorder before and after school entry: Relating interventions to developmental findings. Development and Psychopathology, 5, 243-262.

Richters, J. E. (1993). Community violence and children's development: Toward a research agenda for the 1990's. Psychiatry, 56, 3-6.

Richters, J. E., \& Cicchetti, D. (1993). Editorial. Toward a developmental perspective on conduct disorder. Development and Psychopathology, 5, l-4.

Richters, J. E., \& Martinez, P. (1993). The NIMH Community Violence Project: Children as victims and witnesses to violence. Psychiatry, 56, 7-21.
Richters, J. E., \& Waters, E. (1991). Attachment and socialization: The positive side of social influence. In M. Lewis \& S. Feinman (Eds.), Social influences and socialization in infancy (pp. 185-213). New York: Plenum Press.

Robins, L. N. (1966). Deviant children grown up. Baltimore, MD: Williams \& Wilkins.

Robins, L. N., \& Regier, D. A. (1991). Psychiatricdisorders in America: The Epidemiological Catchment Area Study. New York: The Free Press.

Rotenberg, M. (1978). Psychopathy and differential insensitivity. In R. D. Hare \& D. Schalling (Eds.), Psychopathic Behavior. New York: Wiley.

Rourke, B. P. (1985). Statistical analysis of large neuropsychological data bases: Methodological and clinical considerations. Journal of Clinical and Experimental Neuropsychology, 7, 631.

Rutter, M. (1986). Child psychiatry: The interface between clinical and developmental research. Psychological Medicine, I6, 151 - 160.

Sarbin, T. (1967). On the futility of the proposition that some people be labeled 'mentally ill.' Journal of Consulting Psychology, 31, 447-453.

Shapiro, S. K., Quay, H. C., Hogan, A. E., \& Schwartz, K. P. (1988). Response perseveration and delayed responding in undersocialized aggressive conduct disorder. Journal of Abnormal Psychology, 97, 37 1-373.

Spitzer, R. L., Sheehy, M., \& Endicott, J. (1977). Guiding principles. In V. M. Rakoff, H. C. Staneer, \& H. B. Keeward (Eds.), Psychiatric diagnosis (pp. 1-24). New York: Bruner/Mazel.

Sroufe, L. A., \& Rutter, M. (1984). The domain of developmental psychopathology. Child Development, 55, 17-29.

Susman, E. J. (1993). Psychological, contextual, and psychobiological interactions: A developmental perspective on conduct disorder. Development and Psychopathology, 5, 181-189.

Szasz, T. S. (1960). The myth of mental illness: Foundations of a theory of personal conduct. New York: Harper \& Row.

Szasz, T. S. (1971). The sane slave. American Journal of Psychotherapy, 25, 228-239.

Taylor, V. A. (1989). The vote on DSM-IV. Archives of General Psychiatry, 46, 959.

Twain, M. (1876/1950). The adventures of Tom Sawyer. Middlesex, England: Penguin Books, Ltd.

Twain, M. (1947). The adventures of Huckleberry Finn. Cleveland, OH: World Publishing.

Wakefield, J. C. (1992a). The concept of mental disorder: On the boundary between biological facts and social values. American Psychologist, 47,373-388.

Wakefield, J. C. (1992b). Disorder as harmful dysfunction: A conceptual critique of DSM-III-R's definition of mental disorder. Psychological Review, 99, 232-247.

Walker, J. L., Lahey, B. B., Russo, M. F., Christ, M. A. G., McBurnett, K., Loeber, R., StouthamerLoeber, M., \& Green, S. M. (1991). Anxiety, inhibition, and conduct disorder in children: Relations to social impairment. Journal of the American Academy of Child and Adolescent Psychiatry, 30, 187-191.

Washington Post (1970, April 10). Dr. Hutschnecker's modest proposal. Washington Post, p. A18.

Waters, E., Vaughn, B., \& Egeland, B. (1980). Individual differences in infant-mother attachment. 
Antecedents in neonatal behavior in an urban economically disadvantaged sample. Child Devefopment, 51, 208-216.

White, J., Moffitt, T. E., Caspi, A., Needles, D. J., \& Stouthamer-Loeber, M. (in press). Measuring impulsivity and examining its relationship to delinquency. In G. P. Sholeva (Ed.), Conduct disorders in children and adolescents: Assessments and interventions. Washington, DC: American Psychiatric Press.

Wilson, M. (1993). DSM-III and the Transformation of American Psychiatry. American Journal ofPsychiatry, 150, 399-410.

Zoccolillo, M. (1992). Co-occurrence of conduct disor- der and its adult outcomes with depressive and anxiety disorders: A review. Journal of the American Academy of Child and Adolescent Psychiatry, 31, 547-556.

Zoccolillo, M., Pickles, A., Quinton, D., \& Rutter, M. (1992). The outcome of childhood conduct disorder: Implications for defining adult personality disorder. Psychological Medicine, 22, 97 1986.

Zubin, J. (1978). But is it good for science? Clinical Psychologist, 31(2), 1-7.

Zubin, J., \& Spring, B. (1977). Vulnerability-A new view of schizophrenia. Journal of Abnormal Psychology, 86, 103-126. 